\title{
Action Plan to Ensure Global Availability of Adrenaline Autoinjectors
}

\author{
Tanno LK ${ }^{1,2,3}$, Demoly $\mathrm{P}^{2,3}$, on behalf of the Joint Allergy Academies* \\ ${ }^{1}$ Hospital Sírio Libanês, São Paulo, Brazil \\ ${ }^{2}$ University Hospital of Montpellier, Montpellier, and Sorbonne Universités, UMR-S 1136, IPLESP, Equipe EPAR, Paris, France \\ ${ }^{3}$ WHO Collaborating Center for Classification Scientific Support \\ * Joint Allergy Academies: American Academy of Allergy Asthma and Immunology (AAAAI), European Academy of Allergy and Clinical \\ Immunology (EAACI), World Allergy Organization (WAO), American College of Allergy Asthma and Immunology (ACAAI), Asia Pacific Association \\ of Allergy, Asthma and Clinical Immunology (APAAACI), Latin American Society of Allergy, Asthma and Immunology (SLAAI)
}

J Investig Allergol Clin Immunol 2020; Vol. 30(2): 77-85

doi: 10.18176/jiaci.0346

\begin{abstract}
Adrenaline (epinephrine) is the first-line treatment for anaphylaxis and, therefore, is listed as an essential medication for the treatment of anaphylaxis by the World Health Organization (WHO). However, the availability of adrenaline autoinjectors (AAI) for use as first-aid treatment is limited to only $32 \%$ of all the world's 195 countries, most of which are high-income countries. The key issues leading to the lack of availability of AAls include cost, national regulations, lack of regional evidence on the value of epinephrine, and limited accurate data about the epidemiology of anaphylaxis. For these reasons, regional and international allergy academies support initiatives to narrow these gaps. Our WHO Collaborating Centre is deeply involved in this process. This document aims to serve as a baseline to ensure the following: (1) adequate access to affordable autoinjectors for all patients/societies; and (2) the development of disease-/patient-specific approaches. Therefore, we propose a 5-step action plan that aims to gather accurate epidemiological data on anaphylaxis and autoinjector consumption, confirm partnerships, strengthen awareness, and include AAls in the WHO Model List of Essential Medicines. These aspects should be considered in combination. A prioritized research agenda should encapsulate all these steps within the framework a global initiative against anaphylaxis. More than calling for universal availability of autoinjectors for optimal management of anaphylaxis, we propose an action plan as the baseline for a global initiative against anaphylaxis. We strongly believe that combined efforts will ensure a strong public health and societal approach that will lead to optimal care of allergic patients and best practices in allergology.
\end{abstract}

Key words: Anaphylaxis. Adrenaline/epinephrine autoinjectors. Classification. Epidemiology. Essential medicine. International Classification of Diseases. Prevention. World Health Organization.

\section{Resumen}

La adrenalina es el tratamiento de primera línea de la anafilaxia y, por lo tanto, está catalogada como un medicamento esencial en su tratamiento por la Organización Mundial de la Salud (OMS). Sin embargo, la disponibilidad de los autoinjectores de adrenalina (AIA), indispensables en las fases iniciales del manejo de la anafilaxia, está limitada a solo el 32\% de los 195 países del mundo, en su mayoría países con economías de primer orden. Los problemas clave que conducen a la falta de disponibilidad de los AIA incluyen el costo, pero también la regulación nacional, la falta de evidencia locales sobre el valor de la epinefrina y la escasez de datos precisos sobre la epidemiología de la anafilaxia. Por estas razones, las sociedades científicas de alergia, nacionales e internacionales, dan apoyo a las iniciativas encaminadas a reducir estas brechas. Nuestro Centro Colaborador de la OMS está profundamente involucrado en este proceso y el propósito de este documento es servir de punto de partida para alcanzar: (I) un acceso adecuado a los AIA a un costo asequible para todos los pacientes/sociedades y (II) el desarrollo de un abordaje específico para el binomio paciente/enfermedad. Por todo ello, proponemos un plan de acción en 5 pasos: recopilar datos epidemiológicos de calidad sobre la anafilaxia e indicadores de consumo de AIA, establecer alianzas entre todos los agentes implicados, reforzar la importancia del uso adecuado de los AIA e incluirlos en el listado de medicamentos esenciales de la OMS, que deben darse de forma conjunta. Una agenda de investigación priorizada debe incluir todos estos pasos en el marco de una iniciativa global contra la anafilaxia. Más que exigir la disponibilidad global de los AIA para un mejor abordaje de la anafilaxia, proponemos un plan de acción como base de una iniciativa mundial contra la anafilaxia. Creemos firmemente que estos esfuerzos combinados a nivel de sociedad y de salud pública conllevarán un cuidado óptimo de los pacientes alérgicos y la mejor práctica de la Alergología.

Palabras clave: Anafilaxia. Autoinyectores de adrenalina/epinefrina. Clasificación. Epidemiología. Medicina esencial. Clasificación Internacional de Enfermedades. Prevención. Organización Mundial de la Salud. 


\section{Epinephrine Autoinjector Availability: A Matter of Life and Death}

\section{The Usefulness of Epinephrine}

Adrenaline (epinephrine) is the first-line treatment for anaphylaxis. All definitions of anaphylaxis for clinical use by health care professionals describe the condition a serious, generalized, allergic or hypersensitivity reaction that can be life-threatening and even fatal [1-4]. Anaphylaxis comprises a constellation of features and signs that are not pathognomonic of a single disease [5]. Adrenaline is the only medication that has been shown to prevent hospitalization, hypoxic sequelae, and death in patients who experience anaphylaxis. As a clearly critical tertiary prevention measure, its availability in some countries is taken for granted, and it is widely available in the community for first-aid treatment.

Adrenaline is listed as an essential medication for the treatment of anaphylaxis by the World Health Organization (WHO) [6]. It is a life-saving nonselective adrenergic agonist, whose $\alpha 1$-adrenergic vasoconstrictor activity prevents and relieves laryngeal edema, hypotension, and shock. Its $\beta 1$-adrenergic activity produces inotropic and chronotropic effects [2], thus increasing the force and rate of cardiac contractions. Its $\beta 2$-activity includes bronchodilation and decreases release of inflammatory mediators. Its effects are time-dependent, and it should be administered quickly. Despite its pivotal role, the autoinjectable formulation is not readily available in most countries [7], thus preventing optimal management of patients with anaphylaxis.

\section{Current Status of the Global Availability of Adrenaline Autoinjectors}

Adrenaline autoinjectors (AAIs) are commercially available in many devices in doses suitable for most, but not all, adults and children. For instance, 4 commercial formulations are available in France (Table 1), although this does not reflect commercial availability in other countries. However, the availability of autoinjectors for emergency treatment of anaphylaxis is limited to $32 \%$ of the 195 countries in the world [7], most of which are high-income countries (Figure 1). In some countries AAIs are not available through official distribution networks, although they can be obtained through distribution by special licensing arrangements and through distribution on a named-patient basis. They can also be obtained through the so-called suitcase trade, an unofficial source that is unreliable because of the possibility of interruptions in the supply and shipping and storage of the devices under conditions outside the recommended temperature range, leading to increased possibility of degradation of the epinephrine content. Although not ideal, in specific situations, where AAIs are not available through official distribution networks, some patients and families can afford to order them online from an international pharmacy or travel to another country to purchase them [8-10]. Lack of availability of this emergency medication for immediate injection in an anaphylactic reaction increases the risk of progression to a severe episode and death.

\section{Action Plan to Provide Adrenaline Autoinjectors for the Prevention of Anaphylaxis Worldwide}

According to the WHO constitution, health is defined as a "state of complete physical, mental and social wellbeing and not merely the absence of disease or infirmity". The WHO also states that "the enjoyment of the highest attainable standard of health is one of the fundamental rights of every human being without distinction of race, religion, political belief, economic or social condition" [11]. With the aim of ensuring good health and care for all, there is a pressing need to step up international and national action on prevention of anaphylaxis and to understand the factors that put individuals at risk of developing anaphylaxis and dying from anaphylaxis.

Table 1. Commercially Available Adrenaline Autoinjectors in France (2018)

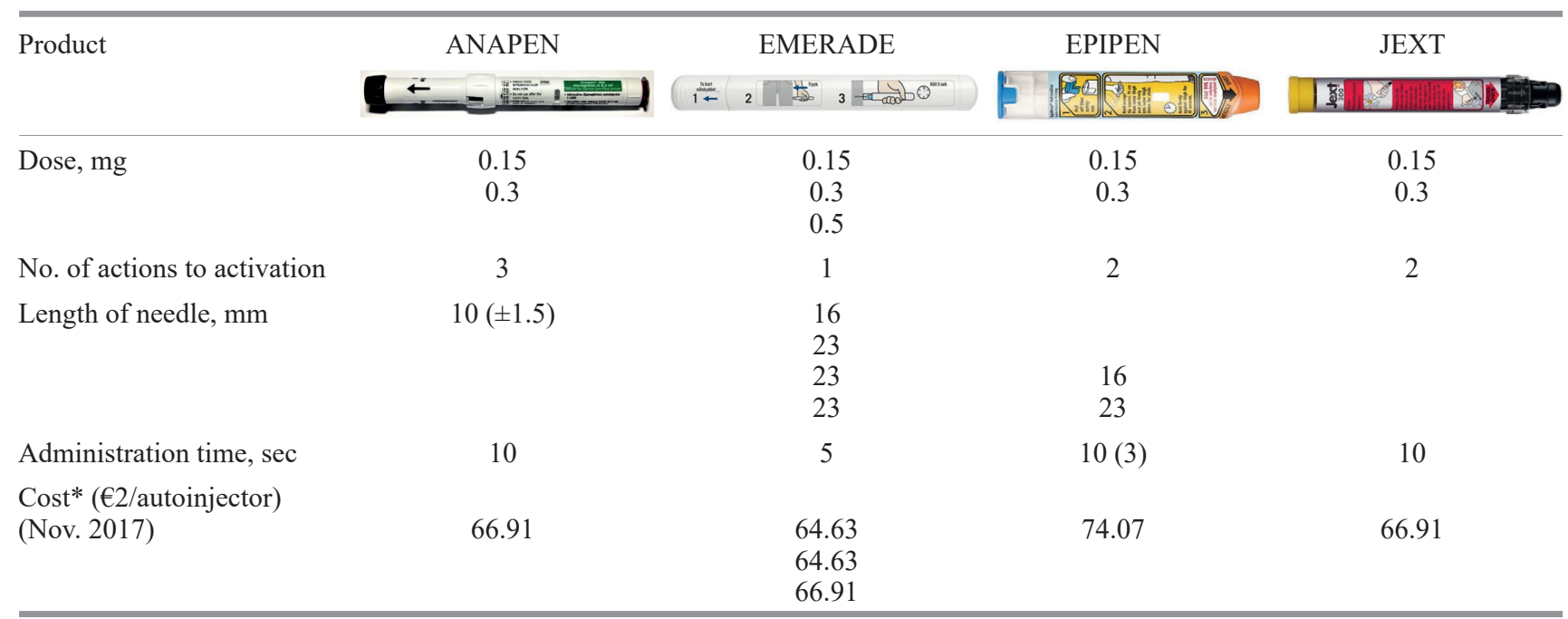

*Reimbursement: $65 \%$ 


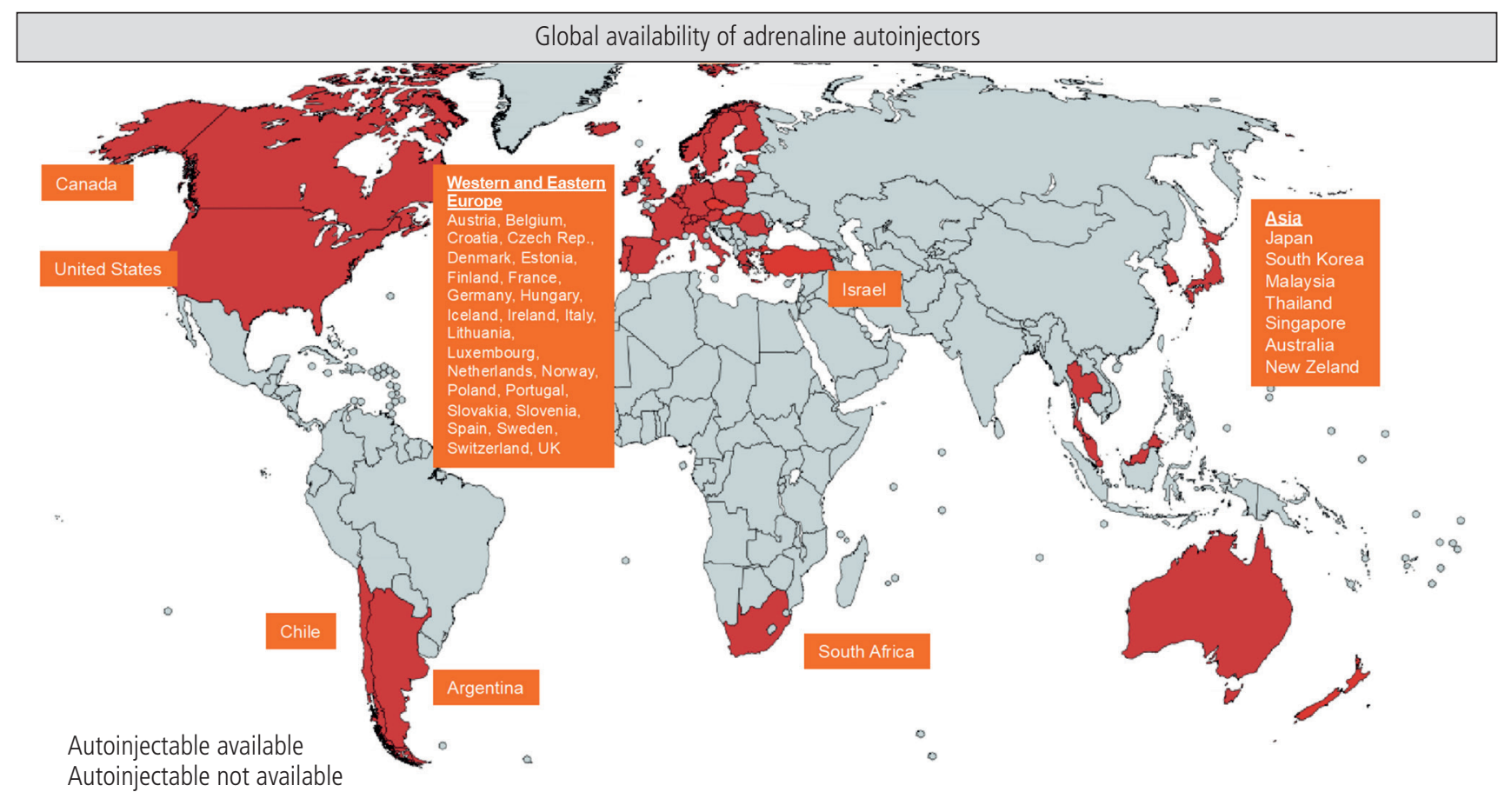

Figure 2. Adrenaline autoinjectors are missing in more than $65 \%$ of countries throughout the world (adapted from Ref 7).

The allergy community is concerned with secondary/tertiary prevention based on accurate diagnosis and management of allergic and hypersensitivity diseases in order to avoid new exacerbations and reactions. In the context of anaphylaxis, which is a multisystem and potentially fatal disorder, all heath care professionals should be prepared to recognize and manage it promptly and properly. Patients, too, should be prepared to recognize and self-treat anaphylaxis promptly. Therefore, AAIs should be globally available as first-line treatment in both private and public settings (eg, school) and health networks to be used by any individual who develops anaphylaxis [7].

Approaches may differ from country to country, depending on national/ regional policies, regulations, and economic status. However, this document aims to act as a baseline from which we can attain the following: (1) adequate access to affordable AAIs for all patients/societies; and (2) disease-/patientspecific approaches. We therefore propose a 5-step action plan (Table 2), which should be considered in combination. The 5 steps are as follows:

(1) To obtain accurate statistics on the morbidity and mortality of anaphylaxis

(2) To confirm partnerships, ie, collaboration with national bodies and stakeholders in order to reach health and/ or social security administrations

(3) To strengthen awareness

(4) To include AAIs in the WHO Model List of Essential Medicines

(5) To provide worldwide data on the consumption of AAIs

Countries with different economic conditions have specific priorities and requirements. The proposed action plan should support countries with different needs. For instance, steps 1, 2, and 4 would be crucial for middle- and low-income countries in which autoinjectors remain largely unavailable. On the other hand, steps 2 and 5 would provide autoinjectors at affordable prices and covered by national health services. Step 3 is a key step in decreasing the number of avoidable deaths throughout the world.

\section{Step I: To Obtain Accurate Statistics on the Morbidity and Mortality of Anaphylaxis}

From a public health perspective, morbidity and mortality data are key parameters of health status and, therefore, the basis for planning and interventions associated with health care and disease prevention.

Currently, the principal and most reliable source for implementing and monitoring public health policies is information derived from cause of death statistics. While this source is well established and provides reliable and comparable public data for most countries, anaphylaxis has never been a possible cause of death on death certificates. A recognized reason for under-notification of fatal anaphylaxis is the difficulty in coding deaths from anaphylaxis under the World Health Organization (WHO) International Classification of Diseases (ICD) system, as demonstrated by Brazilian mortality data [12]. The lack of accurate data on the mortality of anaphylaxis prevents us from providing a comprehensive picture of public health and health interventions and investments, such as increasing the availability of AAIs.

At the global level, data are not collected in a regular and systematic fashion, and statistics on diagnosis-based morbidity are not disseminated [13], because, from a methodological and operational point of view, the collection of morbidity 
Table 2. General Timeline of the Action Plan to Reach Worldwide Availability of Adrenaline Autoinjectors

\begin{tabular}{|c|c|c|}
\hline Action Plan ${ }^{\mathrm{a}}$ & Current Status & Long-term Process \\
\hline $\begin{array}{l}\text { Reach accurate } \\
\text { anaphylaxis } \\
\text { epidemiological } \\
\text { data }\end{array}$ & $\begin{array}{l}\text { - Strengthen standard international definitions, } \\
\text { notification, classification, and coding } \\
\text { (eg, International Classification of Diseases) } \\
\text { to support monitoring of morbidity and } \\
\text { mortality } \\
\text { - Alignment with the WHO for the } \\
\text { implementation of International } \\
\text { Classification of Diseases (ICD-11) } \\
\text { - Changes in the World Health Organization } \\
\text { (WHO) mortality coding rules } \\
\text { - Alignment with the Joint Allergy Academies, } \\
\text { institutions, and experts in the field }\end{array}$ & $\begin{array}{l}\text { - Implementation of ICD-11 and application of the WHO } \\
\text { mortality coding rules } \\
\text { - Surveillance and monitoring }\end{array}$ \\
\hline $\begin{array}{l}\text { Confirm } \\
\text { partnerships }\end{array}$ & $\begin{array}{l}\text { - Acknowledgement from the Joint Allergy } \\
\text { Academies and experts in the field and } \\
\text { collaboration with the WHO } \\
\text { - Establishment of the WHO Collaborating } \\
\text { Centre for Classification and Scientific } \\
\text { Support }\end{array}$ & $\begin{array}{l}\text { - To establish close collaboration with national bodies } \\
\text { in order to implement actions for better patient care, } \\
\text { monitoring, prevention, and developments in research } \\
\text { and to launch measures in order to reduce avoidable } \\
\text { deaths } \\
\text { - To extend these actions internationally with the support } \\
\text { of the WHO Family of International Classifications, } \\
\text { academic and scientific networks, the Joint Allergy } \\
\text { Academies, stakeholders, and patient organizations } \\
\text { - To provide the means through which governmental and } \\
\text { nongovernmental collaborating bodies can combine their } \\
\text { strengths to achieve focused objectives }\end{array}$ \\
\hline $\begin{array}{l}\text { Strengthen } \\
\text { awareness }\end{array}$ & $\begin{array}{l}\text { - The allergy academies have been promoting } \\
\text { education activities, anaphylaxis guidelines, } \\
\text { and public campaigns regarding the possible } \\
\text { manifestations of anaphylaxis }\end{array}$ & $\begin{array}{l}\text { - Increase health professionals' awareness through education } \\
\text { and continuing education programs (eg, breastfeeding, } \\
\text { latex avoidance, early food diversification for infants). } \\
\text { - Support dissemination of accurate information to the } \\
\text { public (eg, European Academy of Allergy and Clinical } \\
\text { Immunology anaphylaxis campaign, World Allergy } \\
\text { Organization allergy week). } \\
\text { - Specific interventions with early introduction of specific } \\
\text { foods in infant diets (eg, peanut). } \\
\text { - Remove strong sensitizers from public places and } \\
\text { workplace environments (eg, remove powdered latex } \\
\text { gloves to prevent occupational latex allergy/ anaphylaxis, } \\
\text { remove over-the-counter use of pholcodine to prevent } \\
\text { anaphylaxis induced by neuromuscular blocking agent). } \\
\text { - Individualize patient education and provide specific } \\
\text { information: environmental or behavioral modifications to } \\
\text { reduce exposure to allergens and a written anaphylaxis } \\
\text { emergency action plan. }\end{array}$ \\
\hline $\begin{array}{l}\text { Include AAI in the } \\
\text { WHO Model List } \\
\text { of Essential } \\
\text { Medicines (EML) }\end{array}$ & $\begin{array}{l}\text { - Proposal under preparation together with } \\
\text { the WHO EML leadership }\end{array}$ & $\begin{array}{l}\text { - After formal inclusion into the EML, this WHO statement } \\
\text { will be offered for possible implementation in different } \\
\text { countries. }\end{array}$ \\
\hline $\begin{array}{l}\text { Provide worldwide } \\
\text { data regarding } \\
\text { the consumption } \\
\text { of autoinjectors }\end{array}$ & $\begin{array}{l}\text { - Indicators mention that the anaphylaxis } \\
\text { segment dominated the global autoinjector } \\
\text { market by indication in terms of revenue } \\
\text { in } 2015 \text { and the trend is expected to be } \\
\text { maintained throughout the forecast period }\end{array}$ & $\begin{array}{l}\text { - Understand trends and gather consistent data regarding } \\
\text { prescription and consumption of autoinjectors are key } \\
\text { data when forecasting the autoinjector market. This will } \\
\text { enable the following: (1) accurate data about the burden } \\
\text { of global anaphylaxis; (2) national interventions to } \\
\text { ensure availability in countries where these medications } \\
\text { are absent; (3) national health policies in order to ensure } \\
\text { that autoinjectors are available in both private and public } \\
\text { settings; (4) the dialog with national bodies, regulators, } \\
\text { and stakeholders to ensure the availability of medications } \\
\text { at an affordable price for all or full reimbursement from } \\
\text { national security. }\end{array}$ \\
\hline
\end{tabular}

${ }^{a}$ Action Plan to Reach Worldwide Availability of Epinephrine Autoinjectors for the Prevention of Anaphylaxis 
statistics is an extremely complex exercise, in particular with regards to comparability of data across countries. Populationbased morbidity data mainly use the ICD as a means of harmonizing data. However, a limited number of $I C D-10$ codes capture anaphylaxis data. In $I C D-10$, there are only 2 terms for anaphylaxis, and these are hidden within section T78 of Other and unspecified effects of external causes under the unsatisfactory title Adverse effects, not elsewhere classified. To date, these difficulties have hampered attempts to collect morbidity data based on (mainly) administrative data, similar to those already existing for causes of death or for health care data based on hospital discharges. Regional epidemiological data on anaphylaxis differ considerably according to many variables, and it is still unclear whether the increasing incidence published is real or the results reflect differences in the methods used to define and characterize anaphylaxis [14].

New perspectives in collection of statistics on the morbidity and mortality of anaphylaxis may develop with the implementation of ICD-11 in the coming years. ICD-11 should enable better representation of anaphylaxis through the pioneering section "Allergic and hypersensitivity conditions" in the "Disorders of the immune system" chapter $[15,16]$. This achievement was the a result of combined international academic and evidence-based trajectory acknowledged by the Joint Allergy Academies, which comprise 6 regional international allergy academies (the American Academy of Allergy, Asthma \& Immunology; the European Academy of Allergy and Clinical Immunology; the World Allergy Organization; the American College of Allergy, Asthma, and Immunology; the Asia Pacific Association of Allergy, Asthma and Clinical Immunology; and the Latin American Society of Allergy, Asthma and Immunology) and the ICD representatives of the WHO [12,15,17-29]. Meanwhile, we have been working to change the WHO mortality coding rules in order to consider anaphylaxis an underlying cause of death on death certificates [30]. The new ICD-11 will not solve all the problems related to population-based mortality and morbidity statistics, such as the presence of over- or underdiagnosis as a result of coding by persons who are not experts in this disease (doctors or coders). For this reason, our WHO Collaborating Centre is developing training tools to prepare worldwide endusers for the implementation of $I C D-11$.

Field-testing and validation procedures have been performed to support the implementation of $I C D-11$. The utility of the new "Anaphylaxis" section has been evaluated from the perspective of morbidity and mortality [25-29]. One of the tasks of our WHO Collaborating Center is to follow the "Allergic and hypersensitivity conditions" section and promote the required refinements.

\section{Step II: Confirm Partnerships: Collaboration With National Bodies and Stakeholders in Order to Reach Health and/or Social Security Administrations}

A coordinated action plan is required. This should be supported at the highest levels of government and include health concerns in all policy-making areas, from trade and finance to education and environmental planning. The action plan needs to go beyond government and should bring in civil society, academia, business, and other stakeholders to promote health.
For instance, the French Ministry of Health, in coordination with the State Secretariat for Higher Education and Research, implements a proactive policy based on the mobilization of health/research professionals and patients' associations in order to improve the quality of diagnosis, management, and prevention for the 3 million patients affected by rare diseases in France. These organizations use the Orphanet portal of the French National Institute for Health and Medical Research (INSERM), which makes useful information for on rare diseases and orphan drugs available to physicians and patients. Created in 1997 in France, it was extended throughout Europe in 2000 thanks to grants from the European Commission (https://www.orpha.net/consor/cgi-bin/index.php?lng=EN). Although severe anaphylaxis is still not on the list of rare diseases, its inclusion would enable the allocation of resources to better understand the national and global epidemiology of anaphylaxis as a disease and monitoring of the patterns of this disorder to record hospitalizations, mortality, avoidable deaths, and costs. Having more precise epidemiological data could support the availability of epinephrine autoinjectors worldwide at an affordable price. The importance of these devices for patient health care can be stressed in discussion with national bodies and stakeholders. The health intervention/policy model set out above can be taken as an example in various countries for implementation of essential actions according to individual national needs, such as the availability of autoinjectors in low-income countries [14]. It is unknown whether this strategy will make more financial resources available than previous strategies. However, it is important to remember that anaphylaxis is more frequent than previously thought and has increased in prevalence in recent decades, mainly due to the increased frequency of atopy and food allergies. Consequently, more resources are necessary to promote their prevention and treatment. Such an approach could highlight the epidemiology of the disease and thus ensure that a program was implemented.

Publications on the epidemiology of anaphylaxis are hampered by the inclusion of all degrees of severity. Mild reactions, in which manifestations are generally limited to a single organ or system, such as the skin, do not usually carry a risk of death. The inclusion of these cases in epidemiological studies creates a mistaken perception that the incidence of severe anaphylaxis is high and increasing. We wish to address severe reactions in which the risk of mortality is strong and requires additional preventive measures and coordinated management, such as that provided by the rare disease network in France. No data have been published on severe cases of anaphylaxis in Europe. Data from the University of Montpellier suggest that fewer than 30000 people are affected by severe anaphylaxis (9.2 per 100000 person-years) [28]. Data from Australia demonstrated that the number of patients at risk of anaphylaxis increased from $0.98 \%$ in 2009 to $1.38 \%$ in 2014 in school-aged children. In contrast, the number of epinephrine autoinjectors activated (severe cases) per year per 1000 students at risk of anaphylaxis was 6 in 2010 and 8 in 2014 [31]. If taken as isolated data of patients at risk, these figures can lead readers to think that the incidence of anaphylaxis is increasing in Australia. However, the administration of the treatment as objective data indicates that severe anaphylaxis can be considered a rare disease. 
As the only WHO Collaborating Centre in the world working on classifications of allergic and hypersensitivity conditions, we intend to cooperate closely with national bodies in order to implement actions to ensure better patient care and monitoring and disease prevention, to encourage research, and to launch measures aimed at reducing the frequency of avoidable deaths. We also intend to extend these actions internationally with the support of the WHO Family of International Classifications, academic and scientific networks, the Joint Allergy Academies, and stakeholder and patient organizations. Our WHO Collaborating Center will provide the means through which governmental and nongovernmental bodies can combine their strengths to achieve focused objectives and thus avoid wasting energy and resources. A WHO Collaborating Centre is well placed for bilateral dialog with these bodies and fast, easy communication with health organizations. We aim to start the action plan with anaphylaxis as a model, although we may extend the plan to other allergic and hypersensitivity conditions in the coming years. Human and financial resources can be obtained through the support of the above-mentioned bodies, robust research projects, and structured collaborations. This support will enable us to implement the action plan. Structured collaborations are now being developed.

In the field of anaphylaxis, it is mandatory to sensitize the health system at all its levels in order to enhance involvement and proactiveness. The first key goals of the project are to ensure the availability of essential medications for patients, specifically in low- and middle-income countries, and to promote better management and education in high-income countries.

\section{Step III: To Strengthen Awareness}

The main goals of preventive interventions are to reduce the negative impact or progression of an established condition and to reduce complications and the risk of new reactions. In high-income countries, considerable achievements have been reported at both the individual and the population levels (Figure 2) through improved awareness and diagnostic workup. However, we still observe discrepancies in low- and lowto-middle-income countries, where supplementary diagnostic tools, such as tryptase measurements and high priority medications are not available [7].

Increased awareness in the field of anaphylaxis is a key step forward if we are to optimize the patient's journey along health care pathways up to the full allergological work-up. It will be necessary to ensure consistent and bilateral collaboration with general practitioners, pediatricians, various specialties, and other health professionals.

Also important is a personalized health plan including educational guidance based on specific structured diagnostic and preventive measures that would play a key role in decreasing the number of avoidable hospitalizations and deaths. This should include education programs to avoid inadvertent exposures (eg, to food) and instructions for patients and relatives on how to recognize episodes of anaphylaxis. Patients and relatives should be aware that late administration of adrenaline, which increases the risk of death, is due to the following: (1) difficulties in recognizing the manifestations; (2) absence of first-line treatment at the time of the reaction; (3) lack of familiarity with AAIs.

\section{Step IV: To Include AAls in the World Health Organization Model List of Essential Medicines}

The WHO Model List of Essential Medicine contains the medications considered to be most effective and safe for meeting the main needs in the health system. The list is frequently used by countries to support the development of their own local lists of essential medicines $[6,32]$.
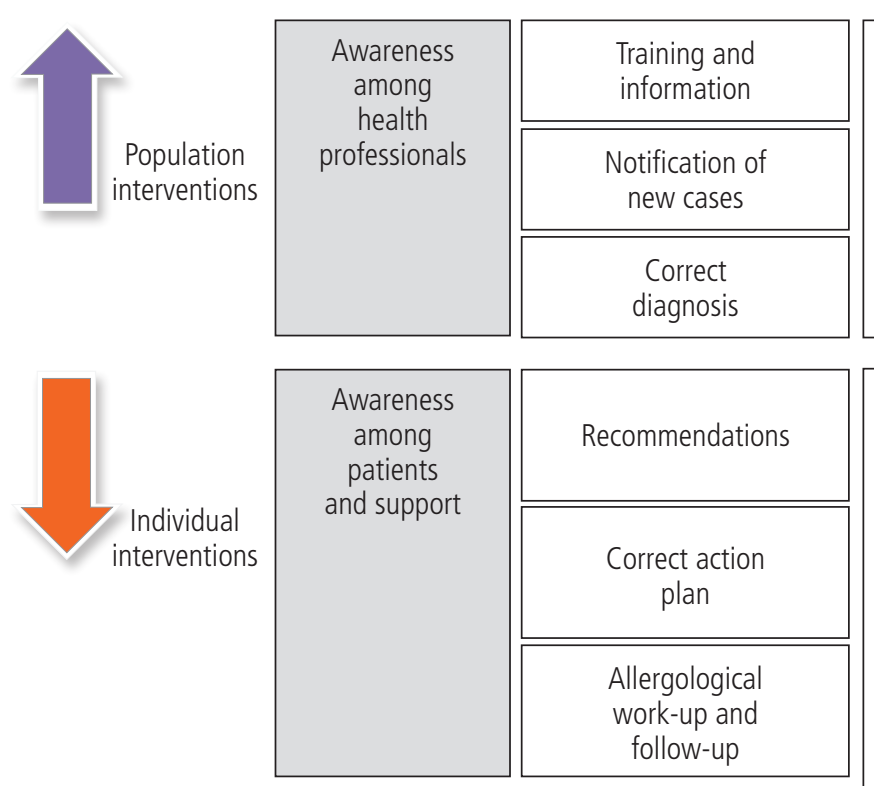

- Increase health professionals' awareness through education and continuing education programs (eg, breastfeeding, latex avoidance, early food diversification for infants).

- Support dissemination of accurate information to the public (eg, EAACI Anaphylaxis campaign, WAO Allergy Week).

- Support accurate food allergen labelling to protect consumers.

- Correct notification of new cases (eg, as new allergens arise, support large cohort analysis).

- Complete allergological work-up to confirm triggers (inducers) and support specific immunomodulation (eg, allergen immunotherapy for hymenoptera venom anaphylaxis or full drug allergy work up as indicated) and provide a written documentation of the diagnosis and the confirmed triggers/agents.

- Individualize patient's education and provide specific information: environmental or behavior modifications to reduce patient's exposure to allergens, provide a written anaphylaxis emergency action plan.

- Support the emergency training of patients and health professionals to rapidly identify and manage anaphylaxis.

Figure 2. Strengthening awareness to prevent anaphylaxis. 
The first list was published in 1977 and included 212 medications. The 20th edition was published in 2017 and comprises 433 drugs [32]. Although epinephrine is listed as the treatment of anaphylaxis, the autoinjector format is still missing from the list. If included, it could be published in the national lists of countries where these drugs are not available. For this reason, the discussions with the WHO list representatives are ongoing, and the proposal will be formally submitted for the forthcoming edition. This move can support arguments to advocate for the adequate treatment of anaphylaxis worldwide.

\section{Step V: To Provide Worldwide Data on the Consumption of AAls}

The feasibility, effectiveness, and affordability of prevention and management strategies play a critical role in reducing preventable deaths. Knowledge of prescription and consumption of autoinjectors are key data when forecasting the autoinjector market. According to the global autoinjector market analysis and forecast, anaphylaxis dominated the global autoinjector market by indication in terms of revenue in 2015, and the trend is expected to continue throughout the forecast period $[33,34]$. Anaphylaxis is the most attractive segment in the field, with an attractiveness index of 3.55 over the forecast period. Revenue from the anaphylaxis segment is expected to register a compound annual growth rate of $15 \%$ during 20162026 and to reach more than US\$ 6 billion by 2026 [33].

Understanding trends in the market of essential medications, such as AAIs, can help the allergy community to ensure the following: (1) accurate data on the burden of global anaphylaxis; (2) national interventions to ensure availability in countries where these medications are absent; (3) national health policies that will guarantee availability of autoinjectors in both private and public settings; (4) dialog with national bodies, regulators, and stakeholders to ensure that medications are available at an affordable price to all or full reimbursement from social security.

Availability of AAIs as a public health measure is open to criticism in that it only benefits individuals who have been suitably diagnosed and can afford and maintain a safe unexpired supply of the devices. Nevertheless, according to the United States Internal Revenue Service, from a prevention perspective, medications are considered preventive care when taken by a person who has developed risk factors for a disease that has not yet manifested itself or not yet become clinically apparent, or to prevent the recurrence of a disease from which a person has recovered [35].

As an example, in 2013, the School Access to Emergency Epinephrine Act was passed in the United States of America. This federal legislation provides a financial incentive for states to enact their own laws requiring schools to keep nonspecific epinephrine autoinjectors in case of an emergency [36]. Nearly every state has passed legislation regarding stocking undesignated epinephrine autoinjectors in primary and secondary schools. Similarly, the state of Florida passed a law to allow public facilities such as amusement parks, sports leagues, camps, city parks, restaurants, and other businesses to store a large number of AAIs for emergency treatment of anaphylaxis [37]. AAI manufacturers recently introduced generic versions in order to reduce the overall cost of the device. The initial pack of 2 devices was sold at US\$600 till December 2016, although this was reduced to US\$300 for the generic form from January 2017, thus enabling both insured and noninsured patients to obtain the medication [33].

Governmental and nongovernmental bodies, international and national allergy organizations, manufacturers, and humanitarian agencies should work together to encourage companies with established distribution networks to include AAIs in their distribution networks. National allergy organizations can play a key role in discussions and actions with national regulators and governmental bodies.

The key issues leading to the lack of availability of AAIs include cost, national regulations, lack of regional evidence on the value of epinephrine, and limited accurate data on the epidemiology of anaphylaxis (morbidity and mortality). During recent years, an increasing number of clinical databases have been developed to capture reliable epidemiological data on anaphylaxis at both national and regional levels [38-45]. However, a substantial proportion of the current data on the epidemiology of anaphylaxis is from registries with limited scope and population sources. Different methods have been applied in an attempt to ensure reliable epidemiological data, although most of the studies have focused on specific triggers or at-risk populations. The lack of harmonized strategies to record cases of anaphylaxis hampers collection of comparable epidemiological data. In general, registries are representative sources of epidemiological data and are applied only if the reporting of the conditions is mandatory and the data are validated. For these reasons, regional and international allergy academies support the initiatives to narrow these gaps.

A prioritized research agenda should encapsulate all the previous steps within the framework of a global initiative against anaphylaxis. More than calling for the global availability of AAIs for optimal management of anaphylaxis to prevent undue morbidity and mortality, we here propose an action plan as the baseline for a global initiative against anaphylaxis. We believe that combined efforts ensure a strong public health and societal approach that will lead to optimal care of allergic patients and best practices in allergology.

\section{Acknowledgments}

We are grateful to all the representatives of the $I C D-11$ reviewed team with whom we have held fruitful discussions that helped us to fine-tune our classification: Robert Jakob, Linda Best, Nenad Kostanjsek, Linda Moskal, Robert J. G. Chalmers, Jeffrey Linzer, Linda Edwards, Ségolène Ayme, Bertrand Bellet, Rodney Franklin, Matthew Helbert, August Colenbrander, Satoshi Kashii, Paulo E. C. Dantas, Christine Graham, Ashley Behrens, Julie Rust, Megan Cumerlato, Tsutomu Suzuki, Mitsuko Kondo, Hajime Takizawa, Nobuoki Kohno, Soichiro Miura, Nan Tajima, and Toshio Ogawa.

\section{Funding}

Pascal Demoly and Luciana Kase Tanno received unrestricted Novartis and grants from MEDA/Mylan Pharma through the CHRUM administration. 


\section{Conflicts of Interest}

The authors declare that they have no conflicts of interests.

\section{References}

1. Sampson HA, Munoz-Furlong A, Campbell RL, Adkinson NF Jr, Bock SA, Branum A, et al. Second symposium on the definition and management of anaphylaxis: summary report - Second National Institute of Allergy and Infectious Disease/Food Allergy and Anaphylaxis Network Symposium. J Allergy Clin Immunol. 2006;117:391-7.

2. Simons FER, Ardusso LR, Bilò MB, Cardona $V$, Ebisawa $M$, El-Gamal YM, et al. International consensus on (ICON) Anaphylaxis. World Allergy Organ J. 2014;30;7-9.

3. Panesar SS, Javad S, de Silva D, Nwaru BI, Hickstein L, Muraro $A$, et al. on behalf of the EAACI Food Allergy and Anaphylaxis Group. The epidemiology of anaphylaxis in Europe: a systematic review. Allergy. 2013;68:1353-61.

4. Lieberman P, Nicklas RA, Randolph C, Oppenheimer J, Bernstein $D$, Bernstein J et al. Anaphylaxis-a practice parameter update 2015. Ann Allergy Asthma Immunol. 2015 Nov;115(5):34184.

5. Simons FER, Ebisawa M, Sanchez-Borges $M$, Thong BY, Worm M, Tanno LK, et al. 2015 update of the evidence base: World Allergy Organization anaphylaxis guidelines. World Allergy Organ J. 2015 Oct 28;8(1):32.

6. WHO Model List of Essential Medicines, 19th ed, April 2015. Available at: http://www.who.int/medicines/publications/ essentialmedicines/EML_2015_FINAL_amended_NOV2015. pdf?ua=1. Accessed June 2017.

7. Tanno LK, Simons FER, Sanchez-Borges M, Cardona V, Moon $H B$, Calderon MA, et al.; Joint Allergy Academies. Applying prevention concepts to anaphylaxis: A call for worldwide availability of adrenaline auto-injectors. Clin Exp Allergy. 2017 Sep;47(9):1108-14.

8. Simons FER. Lack of worldwide availability of epinephrine auto-injectors for outpatients at risk of anaphylaxis. Ann Allergy Asthma Immunol. 2005;94:534-8.

9. Simons FER, for WAO. Epinephrine auto-injectors: first-aid treatment still out of reach for many at risk of anaphylaxis in the community. Ann Allergy Asthma Immunol. 2009;102:403-9.

10. Simons FER, for WAO. World Allergy Organization survey on global availability of essentials for the assessment and management of anaphylaxis by allergy-immunology specialists in healthcare settings. Ann Allergy Asthma Immunol. 2010;104:405-12.

11. World Heath Organization website (Available at: http://www. who.int/about/mission/en/ Last accessed: June 2018)

12. Tanno LK, Ganem F, Demoly P, Toscano CM, Bierrenbach AL. Undernotification of anaphylaxis deaths in Brazil due to difficult coding under the ICD-10. Allergy 2012;67:783-9.

13. Morbidity statistics in the EU, report in pilot studies, 2014 Edition (Available at: http://europa.eu/, accessed June 2018).

14. Tanno LK, Bierrenbach AL, Simons FER, Cardona V, Thong BY, Molinari N, et al; on behalf the Joint Allergy Academies. Critical view of anaphylaxis epidemiology: open questions and new perspectives. Allergy Asthma Clin Immunol. 2018 Apr 4;14:12.
15. Tanno LK, Calderon MA, Demoly P; on behalf the Joint Allergy Academies. New Allergic and Hypersensitivity Conditions Section in the International Classification of Diseases-11. Allergy Asthma Immunol Res. 2016 Jul;8(4):383-8.

16. World Health Organization, ICD-11 Beta Draft website (Available at: http://apps.who.int/classifications/icd11/ browse/l-m/en Accessed June 2018).

17. Tanno LK, Calderon MA, Goldberg BJ, Akdis CA, Papadopoulos NG, Demoly P. Categorization of Allergic Disorders in the New World Health Organization International Classification of Diseases. Clin Transl Allergy. 2014;4:42.

18. Demoly P, Tanno LK, Akdis CA, Lau S, Calderon MA, Santos $A F$, et al. Global classification and coding of hypersensitivity diseases - An EAACI - WAO survey, strategic paper and review. Allergy. 2014;69:559-70.

19. Tanno LK, Calderon MA, Goldberg BJ, Gayraud J, Bircher AJ, Casale T, et al. Constructing a classification of hypersensitivity/ allergic diseases for ICD-11 by crowdsourcing the allergist community. Allergy. 2015;70:609-15.

20. Tanno LK, Calderon M, Papadopoulos NG, Demoly P. Mapping hypersensitivity/allergic diseases in the International Classification of Diseases (ICD)-11: cross-linking terms and unmet needs. Clin Transl Allergy. 2015;5:20.

21. Tanno LK, Calderon MA, Demoly P; on behalf the Joint Allergy Academies. Making allergic and hypersensitivity conditions visible in the International Classification of Diseases-11. Asian Pac Allergy. 2015;5:193-6.

22. Tanno LK, Calderon MA, Demoly P; on behalf the Joint Allergy Academies. Optimization and simplification of the allergic and hypersensitivity conditions classification for the ICD-11. Allergy. 2016 May;71(5):671-6.

23. Tanno LK, Calderon MA, Papadopoulos NG, Sanchez-Borges $M$, Rosenwasser LJ, Bousquet J, et al. Revisiting Desensitization and Allergen Immunotherapy Concepts for the International Classification of Diseases (ICD)-11. J Allergy Clin Immunol Pract. 2016 Jul-Aug;4(4):643-9.

24. Tanno LK, Calderon MA, Li J, Casale T, Demoly P. Updating Allergy/Hypersensitivity diagnostic procedures in the WHO ICD-11 revision. J Allergy Clin Immunol Pract. 2016 JulAug;4(4):650-7.

25. Tanno LK, Calderon MA, Papadopoulos NG, Sanchez-Borges M, Moon HB, Sisul JC, et al.; Joint Allergy Academies. Surveying the new allergic and hypersensitivity conditions chapter of the International classification of diseases (ICD)-11. Allergy. 2016 Sep;71(9):1235-40.

26. Tanno LK, Calderon M, Demoly P; Joint Allergy Academies. Supporting the validation of the new allergic and hypersensitivity conditions section of the World Health Organization International Classification of Diseases-11. Asia Pac Allergy. 2016 Jul;6(3):149-56.

27. Tanno LK, Calderon M, Sublett JL, Casale T, Demoly P; Joint Allergy Academies. Smoothing the transition from International Classification of Diseases, Tenth Revision, Clinical Modification to International Classification of Diseases, Eleventh Revision. J Allergy Clin Immunol Pract. 2016 Nov - Dec;4(6):1265-7.

28. Tanno LK, Molinari N, Bruel S, Bourrain JL, Calderon MA, Aubas $\mathrm{P}$ et al; Joint Allergy Academies. Field-testing the new anaphylaxis' classification for the WHO International Classification of Diseases-11 revision. Allergy. 2017 May;72(5):820-6. 
29. Tanno LK, Bierrenbach AL, Calderon MA, Sheikh A, Simons FE, Demoly $\mathrm{P}$; Joint Allergy Academies. Decreasing the undernotification of anaphylaxis deaths in Brazil through the International Classification of Diseases (ICD)-11 revision. Allergy. 2017 Jan;72(1):120-5.

30. Tanno LK, Simons FE, Annesi-Maesano I, Calderon MA, Aymé S, Demoly P; Joint Allergy Academies. Fatal anaphylaxis registries data support changes in the who anaphylaxis mortality coding rules. Orphanet J Rare Dis. 2017 Jan 13;12(1):8.

31. Loke P, Koplin J, Beck C, Field M, Dharmage SC, Tang ML, et al. Statewide prevalence of school children at risk of anaphylaxis and rate of adrenaline autoinjector activation in Victorian government schools, Australia. J Allergy Clin Immunol. 2016 Aug; 138(2):529-35.

32. Wirtz VJ, Hogerzeil HV, Gray AL, Bigdeli $M$, de Joncheere $C P$, et al. "Essential medicines for universal health coverage". Lancet. 2017;389 (10067):403-76.

33. Global Auto-Injectors Market, Future Market Insights website (Available at: https://www.futuremarketinsights.com/reports/ auto-injectors-market/toc Accessed June 2018).

34. Flabbee J, Petit N, Jay N, Guénard L, Codreanu F, Mazeyrat R et al. The economic costs of severe anaphylaxis in France: an inquiry carried out by the Allergy Vigilance Network. Allergy. 2008 Mar;63(3):360-5.

35. US Internal Revenue Service. Internal Revenue Bulletin: 2004-33. Notice 2004-50. Available at: https://www.irs.gov/ irb/2004-33_IRB/ar08.html\#d0e1823. Accessed 20 March 2016.

36. The United States legislation report, November 13th 2013 (Available at: https://www.whitehouse.gov/blog/2013/11/13/ president-obama-signs-new-epipen-law-protect-childrenasthma-and-severe-allergies-an https://www.congress.gov/ bill/113th-congress/senate-bill/1503, Accessed September 2016)

37. The United States legislation report, June 13th 2014 (Available at: http://knowledgecenter.csg.org/kc/system/files/ Emergency\%20Allergy\%20Treatment.pdf, Accessed June 2018)

38. Worm M, Moneret-Vautrin A, Scherer K, Lang R, FernandezRivas $M$, Cardona $V$, et al. First European data from the network of severe allergic reactions (NORA). Allergy. 2014 Oct;69(10):1397-404.

39. Grabenhenrich LB, Dölle S, Moneret-Vautrin A, Köhli A, Lange $\mathrm{L}$, Spindler $\mathrm{T}$, et al. Anaphylaxis in children and adolescents:
The European Anaphylaxis Registry. J Allergy Clin Immunol. 2016 Apr;137(4):1128-37.

40. Solé $D$, Ivancevich JC, Borges MS, Coelho MA, Rosário NA, Ardusso L, et al.; Latin American Anaphylaxis Working Group. Anaphylaxis in Latin American children and adolescents: the Online Latin American Survey on Anaphylaxis (OLASA). Allergol Immunopathol (Madr). 2012 Nov-Dec;40(6):331-5.

41. Tejedor Alonso MA, Moro Moro M, Múgica García MV. Epidemiology of anaphylaxis. Clin Exp Allergy. 2015 Jun;45(6):1027-39.

42. Ma L, Danoff TM, Borish L. Case fatality and population mortality associated with anaphylaxis in the United States. J Allergy Clin Immunol 2014;133:1075-83.

43. Jeppesen AN, Christiansen CF, Frøslev $T$, Sørensen HT. Hospitalization rates and prognosis of patients with anaphylactic shock in Denmark from 1995 through 2012. J Allergy Clin Immunol. 2016;137:1143-7.

44. Turner PJ, Gowland MH, Sharma V, lerodiakonou D, Harper N, Garcez T, et al. Increase in anaphylaxis-related hospitalizations but no increase in fatalities: an analysis of United Kingdom national anaphylaxis data, 1992-2012. J Allergy Clin Immunol. 2015;135:956-63.

45. Poulos LM, Waters AM, Correll PK, Loblay RH, Marks GB. Trends in hospitalizations for anaphylaxis, angioedema, and urticaria in Australia, 1993-1994 to 2004-2005. J Allergy Clin Immunol 2007;120:878-84.

Manuscript received August 17, 2018; accepted for publication October 26, 2018.

\section{Luciana Kase Tanno}

\author{
Division of Allergy \\ Department of Pulmonology \\ Hôpital Arnaud de Villeneuve \\ University Hospital of Montpellier \\ 371, av. du Doyen Gaston Giraud \\ 34295, Montpellier cedex 5, France \\ E-mail: luciana.tanno@gmail.com
}

